\title{
Comunicação
}

[Communication]

\section{Levantamento de animais silvestres atropelados em trecho da rodovia BR482}

[Survey of road-killed wild animals in stretch of the highway BR482]

\author{
C.M. Sássi ${ }^{1}$, A.A.T. Nascimento ${ }^{2}$, R.F.P. Miranda ${ }^{3}$, G.D. Carvalho ${ }^{4 *}$ \\ ${ }^{1}$ Médico veterinário autônomo \\ ${ }^{2}$ Centro de Controle de Zoonoses - CCZ - Conselheiro Lafaiete, MG \\ ${ }^{3}$ Faculdade de Ciências Biológicas e da Saúde - Facisa/Univiçosa -Viçosa, MG \\ ${ }^{4}$ Instituto Federal Norte de Minas Gerais - IFNMG - Salinas, MG
}

O atropelamento de animais silvestres é um problema grave, porém pouco evidenciado (Silveira, 1999; Rodrigues et al., 2002; Rosa, 2004). Em países europeus, estudos revelam que as rodovias são a causa principal na redução das populações da fauna silvestre (Sorensen, 1995). Conforme Lima e Obara (2004), a grande incidência de animais mortos nas rodovias dá-se por dois motivos: em primeiro lugar, as estradas de rodagem cortam habitats e interferem diretamente no deslocamento natural das espécies; em segundo, há disponibilidade de alimentos ao longo da rodovia. Neste último, apresentam-se o lixo, gerado pelo descaso dos motoristas, os frutos e as sementes das espécies arbustivas e arbóreas próximas à via, e a própria carcaça de animais atropelados, que atrai a mastofauna carnívora.

A busca de informações sobre as dimensões do impacto gerado pelas rodovias tem recebido a atenção de pesquisadores em diversos países (Van der Zande et al., 1980; Kuiken, 1988; Vieira, 1996; Philcox et al., 1999). No Brasil, estes estudos vêm sendo incentivados em áreas de preservação natural (Fischer,, 1997; Faria e Moreni, 2000; Rodrigues et al., 2002).

Ressalta-se que as taxas de atropelamento são, em geral, subestimadas. Os animais que não morrem no momento da colisão deslocam-se para a vegetação adjacente, onde perecem sem serem contabilizados. Pequenos vertebrados mortos são levados rapidamente por necrófagos, enquanto carcaças de animais de médio porte desaparecem da rodovia em período compreendido entre um e 15 dias (Fischer, 1997).

Realizou-se um levantamento de animais silvestres encontrados atropelados no trecho da BR482 entre os municípios de Conselheiro Lafaiete e Viçosa, Minas Gerais, Brasil, no período de agosto de 2008 a maio de 2009, totalizando 43 semanas. Foram realizadas quatro amostragens semanais, no trajeto que compreende $130 \mathrm{~km}$ de deslocamento, totalizando $22.360 \mathrm{~km}$ percorridos. Foram 172 amostragens no período citado, com metade realizada no período da manhã e metade no período da tarde, independentemente do clima e da temperatura.

As viagens eram realizadas por um motorista e dois observadores. Na percepção de qualquer carcaça, o veículo era estacionado para se realizar a identificação e o registro. Todos os animais encontrados atropelados foram fotografados para identificação da espécie, e anotaram-se a proximidade, o local, o horário e a data onde eles foram encontrados. Animais domésticos não foram catalogados. Alguns exemplares, em virtude do atropelamento, não puderam ter sua espécie identificada, sendo somente reconhecidos pela sua classe taxonômica. 
No total, foram encontrados 228 animais atropelados. A Tab. 1 apresenta a relação dos animais atropelados registrados neste estudo, e na Tab. 2 observa-se o total dos animais agrupados por suas classes. Os mamíferos representam a maioria dos animais atropelados, seguidos pelas aves, anfíbios e répteis, nessa ordem. Entre os mamíferos, o principal representante encontrado foi o gambá-deorelhas-pretas (Didelphis marsupialis), um animal oportunista encontrado em diversos tipos de habitats (Nowak, 1999), com o achado de 85 cadáveres.

Considerando o total de quilômetros percorridos neste estudo, a média de atropelamentos foi de 0,010 animais $/ \mathrm{km}$ percorrido. Jácomo et al. (1996) encontraram uma média de 0,06 animais/km, e Silveira (1999) 0,045 animais/km, ambos em trabalhos realizados em rodovias do Parque Nacional das Emas, Goiás, Brasil.

Animais silvestres atropelados, conhecidos como "fauna de estrada", podem servir como indicadores da biodiversidade local, além de fornecerem dados ecológicos sobre a história natural de algumas espécies. Monitorar a fauna de estrada pode revelar aspectos interessantes, como o padrão de deslocamento e a dinâmica sazonal de algumas populações de espécies presentes na comunidade. Com essas informações, pode-se avaliar o grau de conservação local e estabelecer áreas prioritárias para a conservação (Fischer, 1997).

Apesar de o trecho da BR482 compreendido entre os municípios de Conselheiro Lafaiete e Viçosa ser margeado, em quase toda sua extensão, por pastagens e áreas degradadas, é grande a diversidade e abundância de animais susceptíveis de serem atropelados ao longo desse trecho. Há pequenos remanescentes de mata nas margens da estrada, que servem de abrigo ou pontos de dispersão para esses animais. As margens da rodovia apresentam áreas de urbanização, remanescentes de mata, pastagem, plantações temporárias, pedreiras e olarias, evidenciando a ação antropológica negativa sobre a fauna da região.

Tabela 1. Relação dos animais silvestres encontrados atropelados na BR482, no trecho entre os municípios de Viçosa e Conselheiro Lafaiete, em Minas Gerais

\begin{tabular}{lc} 
Nome popular & Número de cadáveres \\
\hline Anfíbios - Anuros (espécies não identificadas) & 6 \\
Anu-preto (Crotophaga ani) & 2 \\
Caxinguelê (Sciurus aestuans) & 3 \\
Cachorro-do-mato (Cerdocyon thous) & 20 \\
Cobra-cega (Amphisbaenia) & 12 \\
Coelho-do-mato (Tapiti) (Sylvilagus brasiliense) & 7 \\
Coruja-buraqueira (Athene cunicularia) & 2 \\
Gambá-de-orelha-branca (Didelphis albiventris) & 85 \\
Gambá-de-orelha-preta (Didelphis marsupialis) & 5 \\
Gavião-carrapateiro (Milvago chimachima) & 2 \\
Gavião-carcará (Caracara plancus) & 1 \\
Mão-pelada (Procyon cancrivorus) & 3 \\
Ouriço-caixeiro (Coendou prehensilis) & 32 \\
Passeriformes (espécies não identificadas) & 13 \\
Pequenos roedores (espécies não identificadas) & 2 \\
Quati (Nasua nasua) & 4 \\
Sagui-de-tufo-preto (Callithrix penicillata) & 6 \\
Seriema (Cariama cristata) & 2 \\
Serpentes (espécies não identificadas) & 2 \\
Tatu-galinha (Dasypus novemcinctus) & 2 \\
Urubu-de-cabeça-preta (Coragyps atratus) & 15 \\
Urutau (Nyctibius griseus) & 3 \\
Total & 228
\end{tabular}


Tabela 2. Classes dos animais silvestres encontrados atropelados na BR482, no trecho entre os municípios de Viçosa e Conselheiro Lafaiete, em Minas Gerais

\begin{tabular}{cc}
$\begin{array}{c}\text { Classes dos animais } \\
\text { atropelados }\end{array}$ & $\begin{array}{c}\text { Número de } \\
\text { cadáveres }\end{array}$ \\
\hline Anfíbios & 26 \\
Aves & 72 \\
Mamíferos & 128 \\
Répteis & 2 \\
Total & 228 \\
\hline
\end{tabular}

Este trabalho, pioneiro na região, apresenta as espécies mais afetadas pelo tráfego de veículos na malha rodoviária da BR482 e contribui para uma avaliação preliminar da fauna atual da região e do impacto causado pela ação antropológica ao longo desse trecho. Porém, são necessários mais estudos para registrar a influência da época do ano, temperatura, tráfego, número de mortes, entre outros fatores.

Palavras-chave: atropelamento, BR482, ecologia de estradas

\begin{abstract}
The objective of this study was to evaluate the occurrence of wild animals found run over on the highway BR482 in the stretch between the cities Conselheiro Lafaiete and Viçosa, Minas Gerais, Brazil. The average of run over was 0.010 animals $/ \mathrm{km}$ traveled. The mammals represented the most hit, followed by birds, amphibians and reptiles. This work, pioneered in this region, presents the species most affected by the traffic in the highway BR482 and contributes to a preliminary assessment of the present fauna of this region and the anthropological impact along that stretch.
\end{abstract}

Keywords: animal trampling, highway BR482, road ecology

\section{REFERÊNCIAS}

FARIA, H.H.; MORENI, P.D.C. Estradas em Unidades de Conservação: impactos e gestão no Parque Estadual do Morro do Diabo, Teodoro Sampaio, SP. In: CONGRESSO BRASILEIRO DE UNIDADES DE CONSERVAÇÃO, II., 2000. Campo Grande. Anais... Campo Grande: [s.n] 2000. p.761-769.

FISHER, W. Efeitos da BR-262 na mortalidade de vertebrados silvestres: síntese naturalística para conservação da região do Pantanal, MS. 1997. 44f. Dissertação (Mestrado em Ciências Biológicas/Ecologia), Universidade Federal do Mato Grosso do Sul, Campo Grande.

JÁCOMO, A.T.A.; SILVEIRA, L.; CRAWSHAW, P.G. Impacto da rodovia estadual GO-341 sobre a fauna do Parque Nacional das Emas, Goiás. In: CONGRESSO DE ECOLOGIA DO BRASIL, 3., 1996. Brasília, Anais... Brasília [s.n.] 1996. p.174.

KUIKEN, M. Consideration of enviroment and landscape factors in higway planning in valued landscapes: in Australian survey. J. of Envirom. Manag., v.6, p.191-201, 1988.
LIMA, S.F.; OBARA, A.T. Levantamento de animais silvestres atropelados na BR-277 às margens do Parque Nacional do Iguaçu: subsídios ao programa multidisciplinar de proteção à fauna. VII Semana de Artes da Universidade Estadual de Maringá, Universidade Estadual de Maringá. 2004. Disponível em $<$ http://www.pec.uem.br/dcu/VII_SAU/sau_traba lhos_6_laudas.htm>. Acessado em 10/11/2006.

NOWAK, R.M. Walker's mammals of the world. 6.ed. Baltimore: The Johns Hopkins University Press, 1999. 517p.

PHILCOX, C.K.; GROGAN, A.L.; MACDONALD, D.W. Patterns of otter Lutra lutra road mortality in Britain. Biol. Conservation, v.36, p.748-762, 1999.

RODRIGUES, F.H.G.; HASS, A.; REZENDE, L.M. et al. Impacto de rodovias sobre a fauna da Estação Ecológica de Água Emendadas-DF. In: CONGRESSO BRASILEIRO DE UNIDADES DE CONSERVAÇÃO, 3., 2002. Fortaleza, Anais... Fortaleza [s.n.] 2002. p.585-593.

ROSA, A.O.; MAUHS, J. Atropelamento de animais silvestres na rodovia RS-040. Caderno de Pesquisa Ser. Bio., v.16, p.35-42, 2004. 
SILVEIRA, L. Ecologia e conservação dos mamíferos carnívoros do Parque Nacional das Emas, Goiás. 1999. 177f. Dissertação, Universidade Federal de Goiás, GO.

SORENSEN, J.A. Road-Kills of badgers (Meles meles) in Denmark. Ann. Zool. Fennici, v.32, p.31-36, 1995.
VAN DER ZANDE, A.N; TER KEURS, W.J.; METIKOSH, S. The impact of roads on the densities of tour birds species in an open field habitat - evidence of a long distance effect. Biol.Conservation, v.18, p.299-321, 1980.

VIEIRA, E.M. Highway mortality of mammals in central Brazil. J. Braz. Associat. Advancement Sci., v.48, p.270-272, 1996. 